\title{
Palliative care in Cuba
}

\author{
Mariuska Forteza Sáez ${ }^{1 *}$, Jorge A Grau Abalo², Dra María del Carmen Llanta ${ }^{2}$ and Débora García Socarrás ${ }^{1}$ \\ ${ }^{1}$ Department of Oncopediatric, National Institute of Oncology and Radiobiology of Cuba \\ ${ }^{2}$ Department of Psychology, National Institute of Oncology and Radiobiology of Cuba
}

\begin{abstract}
Palliative care is a of health care that improve the life quality of patients suffering chronic, debilitating or threatening illnesses, and also that of their careers. The aim of this article was to describe the evolution of Palliative care since its appearance and the tendencies that have characterized their development in the world and in Cuba. We consider documented references that explain how Palliative care has been introduced into many health systems all over the world in recent decades. A large amount of information was collected on interdisciplinary teams as being the main work unit for palliative care in various contexts of both health and the home. Applications of Palliative care were found in priority planning for application in the Cuban Primary Health Care with the intention of restoring the essential human dimensions in these patients and in their careers. It was necessary to study historical sources in order to ascertain the evolution and the fundamental stages of the development, the relation of Palliative care with other elements of the same environment and the collection of widespread information in a general setting that gave form to a single whole in the evolution of Palliative care. As a result, this article historical data of great importance was obtained about how palliative care was introduced and how they evolved in care of critically ill patients suffering chronic or debilitating diseases. At the same time the principles on which Palliative care is sustained were described as were the functions of the interdisciplinary team. Both aspects suppose a theoretical contribution. Work projections in Cuba were put forward for the period 2008-2010 on the basis of the incidence of threatening chronic illnesses in that country.
\end{abstract}

\section{Introduction}

Palliative Care is a model of health care that improves the quality of life of patients with chronic, debilitating or threatening diseases and their caregivers. The purpose of this article was to describe the evolutionary development of Palliative Care since its emergence and the trends that have characterized its development in Cuba. In the course of the history of mankind, the attitude of man before death has not always been the same. In the Middle Ages there was the so-called "domestic death". It consisted of the dying man inviting his loved ones to gather around his bed and perform the so-called "rite of the room" [1]. This ceremony took place in union with the loved ones of those who were about to die.

With the First World War began a process called "forbidden death", where death is separated from the daily events of life [2]. Stop being the expected death, accepted and accompanied to be cornered and eliminated from language as a shameful and strange process. The precursor of palliative medicine Cecily Saunders refers that hiding the dying person, their diagnosis and the truth of their prognosis has become a current trend. In addition, the home is replaced by the hospital as the place for the dying process to occur [3].

The relief of symptoms was the primary task of medical treatment until the end of the 19th century. The medicine already in the twentieth century is heading towards the search of the etiology and the treatment of the diseases providing its cure. It is due to the scientific-technical advances and the increase in life expectancy that the management of the symptoms goes into the background. Currently, the objective pursued by medicine rather than caring for the quality of life of the population is to prolong the life expectancy of them [4].

At present, the treatment indicated by different specialists can only lead to the therapeutic harassment of the patient, instead of attending to the dimensions of the quality of life that may be affected. It is also reflected in the great void that exists in the curricula of medicine and nursing in relation to how to properly care for incurable patients with limited life Sanz and Pascual point out before this circumstance that "we must rescue and rediscover, if possible, the phenomenon of "caring" now eclipsed by the overexpansion of the healing aspects of medicine. We do not have to forget that medicine is born as a response of help, consolation and accompaniment for sick and dying human beings" [5].

\section{Material and method}

For the realization of this article the following methods of scientific investigation were used:

- Logical-Historical: It is linked to the knowledge of the different stages of objects in their chronological succession. To know the evolution of the object or phenomenon of investigation, in this case the Palliative Care, it became necessary to reveal its history, the fundamental stages of its development and the fundamental historical conditions.

- Analysis: The study of an object is made from the relationship that exists between the elements that make up the object as a whole. Here we studied the existing literature on Palliative Care, the principles on which Palliative Care is based, the functions of the interdisciplinary teams, the Palliative Care in Cuba, particularly in the City of Havana and the projections up to the year 2016.

${ }^{\star}$ Correspondence to: Mariuska Forteza Sáez, Department of Oncopediatric. National Institute of Oncology and Radiobiology of Cuba, E-mail: mforteza8324@gmail.com

Key words: palliative care, quality of life, interdisciplinary team

Received: October 08, 2018; Accepted: December 21, 2018; Published: December 28, 2018 
- Synthesis: It is the rational meeting of several dispersed elements in a new totality. For this article, Palliative Care and how it can meet the requirements of the Cuban health system have been taken as essential elements.

\section{Palliative care in Cuba}

In 1992, the Program for Attention to Pain and Palliative Care for Cancer Patients (PADCP) was created in the National Institute of Oncology and Radiobiology (INOR) with a modern approach [6].

In 1994, the first Project was proposed for the creation and operation of the Pain and Palliative Care Clinic at INOR. In 1996, after research for the adaptation and validation of instruments and procedures for the training of personnel in the City of Havana, the Program document was prepared, immediately beginning its implementation in 4 provinces of the country: Santiago de Cuba, Camagüey, Villa Clara and City of Havana. Its general objective was defined as: "to increase the subjective well-being and the quality of life of the oncological patient that requires palliative care and their families through an integral care that considers the physical, social, emotional and spiritual aspects, without affectations for the team of Health". Since then, multiple working meetings were held with the National Pharmacy Directorate for the annual prediction of opioid consumption, courses and conferences were offered at INOR, where several experts and experts from PAHO / WHO visited the country with the objective of know the Program and offer their experiences, bibliographic materials were delivered to several institutions, and 26 specialists from across the country were trained in two international distance courses. In addition, two other projects were created to create an Inpatient Palliative Care Unit $[7,8]$.

The massive training by the national team of the Program of Attention to the Pain and Palliative Care to the oncological patient began in 1998 in 5 provinces of the country, conforming the provincial teams that would be in charge of the training "in cascade". These provincial teams were provided with the auxiliary means to carry out this task. In addition, 3 INOR professionals (1 Bachelor of Nursing and 2 doctors) had in-person scholarships in a Palliative Medicine Unit in Las Palmas de Gran Canaria. Lectures on morphine were offered at a National Workshop of the National Pharmacy Directorate. In spite of the efforts made, the systematic production of oral morphine for the Program could never be achieved. Between 2000 and 2003 another Project was created for the creation of a Palliative Care Unit in the INOR, it was discussed in a Workshop with specialists in September 2004, several boxes of donations were given in medicines and the Drug and Health Plan was elaborated. Material available for the Program on two occasions (1999 and 2000). In 2001, a Multicentre Research Project on the Evaluation of the Pain and Palliative Care Program for the oncological patient was completed, which offered data to be discussed at a meeting of the National Program Commission, defining projections and indicators for its generalization in the coming years. The first formal training course for residents of 1st. to 4 th. of INOR, with the participation of nurses and some specialists from various services of the Institute, a course that is currently established as a module in the training of residents $[7,9]$.

Beginning in 2003, a Collaboration Project with the MediCubaSuiza organization began to be developed, as a central strategy for the development of Palliative Care in the City of Havana, which has undergone different renovations. This Project aimed to create reference centres at the hospital level and at the level of Primary Health Care (PHC), at the "Manuel Fajardo" Hospital and at INOR and at a Municipal Clinic attached to the "Vedado" Polyclinic of the Plaza
Municipality, with administrative headquarters in that Polyclinic, with the objective of developing a municipal pilot plan for the City of Havana. In April 2004, a group of American specialists from the Summa Health System visited the country and held a meeting with Cuban palliativists at the International Press Center, obtaining valuable experience and bibliographical materials in the form of books, brochures and electronic support $[10,11]$.

Between 2003 and 2005, visits were made by English, Australian, Swiss and other specialists to Cuba and numerous conferences and conferences were held in different hospitals in the city and in the International Press Center, initiating a joint investigation among specialists of the Policlínico "Tomás Romay" and the King's College. On October 8, 2005, World Day of Hospices and Palliative Care was celebrated in Havana with several activities. Graduates of different specialties (Nursing, Psychology and Medicine) were carried out, where the topic of palliative care was included, as well as in the masters and in the specialty of Health Psychology [12,13].

In 2005, a training workshop was held for community visitors from the "Plaza" Municipality within the framework of the Revolution Program, who made a survey of needs in relation to the care of patients with advanced cancer. A Palliative Care module was also developed for women with advanced gynaecological cancer as part of the Master's Program in Comprehensive Care for Women for primary care physicians in Venezuela. Two training courses were given in 2005 to professionals of the "Plaza" Municipality, within the framework of the Medicuba-Suiza Project, with more than 40 specialists graduating. Based on these achievements and shortcomings, the Special Working Group (GET-CC), convened by the National Cancer Control Unit of the Ministry of Public Health, establishes different priority projections for the coming period, among which are:

- The development of Palliative Care immersed in a Continuous Care Program for oncological patients, based on the starting point of Primary Health Care, with its recent transformations and extending in stages the patients who join the Program, including those who are undergoing to new treatments product of the development of Molecular Immunology, which would lengthen the survival of the patients with the necessary quality of life [14-17].

- Extension to other provinces with the creation of development focal points; as well as the extension to the remaining municipalities of the City of Havana.

- The increase of the actions of the Program in the City of Havana, taking advantage of the Project with Medicaba Switzerland and the creation of a Municipal Clinic of reference.

- Complete the necessary bank of medicines for the control of symptoms in the actions of support and palliation

- Edit a manual, widely disseminated and used for multiple purposes, with the experience accumulated in Cuba so far.

- Increase exchange and training in specific aspects of ongoing care and palliative care with foreign specialists (Program management, symptom control, family care, etc.).

Develop research and projects in these aspects, considering especially those that allow obtaining indicators of impact and leading to scientific degrees (Masters and Doctorates) $[16,17]$.

The results obtained with the Cuban program (1996-2006):

- 1256 professionals trained in 50 basic courses

- 191 complete teams trained, 176 in APS 
- 7,555 patients attended, $60 \%$ of whom already die at home

- Changes in opioid consumption patterns typical of countries with programs in development

- 2 hospital units in central provinces of the country

\section{Situation in the city of havana at the beginning of the current decade}

New health service in the "Plaza de la Revolución" Municipality through the dispensarization of all patients with advanced cancer and their primary caregivers, with the aim of: "Preserve the subjective wellbeing and the quality of life in the oncological patient diagnosed in advanced stage, when the therapeutic plan is established, continuing during the stage in which survival with quality is sought, and, finally, in the terminal stage of life, in addition to preserving the subjective well-being and quality of life of their relatives, through personalized, interdisciplinary, integral and continuous attention, which considers the physical, social, emotional and spiritual aspects, with the least impact on the health team " [6].

\section{Program achievements until 2010}

Progressive awareness of professionals in the sector

- Systematic training for professionals

- The habit of dying in the hospital is modified

- Availability of strong opioids is stabilized, and adequate use of parenteral morphine is progressively increased

- Progressive incorporation of patients and relatives to the Program, which had been gradually extended

- Increase interest in research activity in the subject

- Greater emotional well-being of the patient, family and team is verified, with a low level of professional burnout

Between 2008 and 2010, a program was developed for the extension of Palliative Care to the 14 municipalities of the City of Havana. APSClinical Surgical Hospitals of the capital. Three research projects were carried out, two of them served as doctoral theses for 2 professors from the Nursing Faculty "Lidia Doce Sánchez". The 2nd Chair of Palliative Care was created in the Faculty "Manuel Fajardo" and a 3rd in the Faculty of Nursing "Lidia Doce Sánchez". There is a document called "National Strategies for Continuous Care for Cancer Patients" that serves as a guide for the implementation of this modality of services. The functions of each of the team members are defined at any level of attention $[17,20]$.

\section{Developed activities}

- Design by the National Group of a 60-hour basic course for all provinces, as part of the Cancer Control Diploma - Program was prepared, $\mathrm{CD}$ was delivered to each province with type-presentations and bibliography

- Identification and successive request of necessary resources (medicines and others) to different instances in the MINSAP, including detailed calculation of doses, jobs and budgets and meetings with laboratories - 2015-2016

- Participation in 1st. version of the Latin American Atlas of Palliative Care, at the request of ALCP [19].
- Over 1,500 patients and primary caregivers from 7 polyclinics have been treated in addition to the patients seen in the PCU of the "Manuel Fajardo" Hospital

- A total of more than 3,000 professionals have been trained

- Some resources have been acquired to facilitate CVs

- With the creation of 3 chairs, 3 guides have been published, one for Palliative Care in general, another for family caregivers and another for prevention and control of work stress and the attrition of professionals who care for the chronically ill.

- Research has been developed with exit to doctoral theses, Master's and diploma in Psychology

- Course with 5 modules of the Diploma to cancer coordinators, organized by the Cancer Observatory of the Provincial Department of Health (DPS), with more than 100 professionals from Havana and Mayabeque

Activities in the province of Havana

Culminates 3rd. edition of the multi-profile Diploma by Chair of Faculty of Medical Sciences "October 10" and 2nd. edition of Diploma by Chair of Faculty of Medical Sciences "Manual Fajardo" - 2016

- Beginning of methodological planning for a Master's Degree at the University of C. Médicas de La Habana - 2016-2017

- Increased care for non-oncological patients, with interdisciplinary teams, for institutional initiatives (Institute of Neurology, Center for Attention to patients with HIV / AIDS, Ibero-American Center for the 3rd Age, Institute of Nephrology, National Center for Rheumatology, etc.) [17].

\section{6 update}

- Results are obtained in research on CV and symptom control in several hospital units to assess care strategies - 2015-2016

- Research on mourning and attitudes towards euthanasia has been developed, leading to dissertations and publications - 2014-2017

- Hospital units have been created in key provinces

Hospital Oncológico de Camaguey y Villaclara, Hospital "Manuel Fajardo" in Havana hospital support team based in Pain Clinic of the Institute of Oncology with External Consultation service - 2015-2017

Between 2016 and 2017, recommendations from a WHO Handbook are analysed in the form of a practical Guide, whose prospective derivations were sent to the Ministry of Public Health, which are essentially summarized as follows: “:

- Tools that facilitate the implementation of a new service for different patients at the SNS levels were proposed

- It was concluded that the contents coincide in essentials with approaches from the 90s first in PADCP and then in 2012 in the Comprehensive Cancer Control Program and with basic postulates of graduates

- It was suggested that it be available to decision-makers and professionals at different levels who will implement it as a new health service

- It was proposed to elaborate resolution or instruction for implementation 
- It was recommended to form a national multi-profile group, with representatives of all the medical specialties involved [17-20].

\section{Education and training}

In 2015, a study was conducted to determine the level of information on palliative care in physicians where 63 doctors from different specialties were surveyed. The $(49.9 \%)$ of the respondents had less than 10 years of graduation and $24(52.1 \%)$ had more than 10 years of work experience at the time of the study. When exploring the aspects that define palliative care, it is observed that $100 \%$ of the doctors answered correctly that palliative care is aimed at reducing suffering and raising the quality of life, 38 (82.6\%) acknowledge that it has the objective to offer a support system to help patients lead a life as active as possible until death occurs and $40(86.9 \%)$ accept that the family should always participate in palliative care. However, they handle elements that contradict the meaning of palliative care, we see that $2(4.3 \%)$ believe they should not be provided in the home, when about $60 \%$ (only in the case of cancer patients), they die in the currently home, 6 (13.0\%) do not recognize the spiritual aspects as part of palliative care and $8(17.4 \%)$ report that they are offered to delay the death of the patient, when the WHO has proposed that palliative care have In order to establish a process that does not accelerate the arrival of death or postpone it, the psychological and spiritual aspects must be integrated into the treatment of the patient and care must be provided at both the home and hospital levels; $100 \%$ of the doctors surveyed correctly recognize that mixed therapeutic strategies should be used (pharmacological and non-pharmacological, biomedical and psychosocial methods) [13].

The existence of myths surrounding the use of morphine was recognized by the subjects investigated. We see that they adequately identify that the route of choice for the parenteral administration of morphine is the subcutaneous $67.4 \%$ of the doctors surveyed, but none recognized that it has no therapeutic ceiling.

At the same time, they maintain erroneous concepts, since $73.9 \%$ consider that their use can lead to drug addiction, $84.9 \%$ that always gives respiratory depression, that tolerance develops quickly so that in the end it will not be as effective (50\% of those investigated) and $34.7 \%$ believe that orally it is ineffective. A similar level of responses is observed in both groups [11].

For the WHO, the consumption of morphine (for medical use) is a good indicator of pain control associated with cancer in different countries. It is an essential condition for pain relief, in a Public Health system that guarantees the general availability of morphine and other opioid derivatives for oral administration or by other routes. Many patients with cancer and other chronic diseases do not receive adequate analgesic treatment, either due to improper use or due to underuse of major opioids. According to this organization, only a small minority of the more than one million people who die every week throughout the world receive palliative care to reduce their suffering. The low use of morphine is combined with inadequate use due to the lack of training and general preparation of professionals, which also occurs in our environment. There are certain myths that associate morphine to the last moments of life and its shortening, precisely because it has been reserved as a last resort in the most dramatic pain processes. The problems of dependence cannot be an excuse, since they are absolutely negligible in terminal processes of medium and short duration and secondary in longer or transitory processes compared with the benefits that the elimination of pain produces to the patient [17-20].

\section{Final considerations}

The characteristics of modern life, the lack of training in the symptomatic and interdisciplinary management of patients with serious diseases in advanced stages, are elements that explain the growing recognition of the need to incorporate Palliative Care into the work of current medicine. Palliative Care has experienced a great development over the last decades worldwide to respond in a timely and effective way to the growing number of patients who would benefit from them. The definition of the principles that sustain palliative care and the functions of the interdisciplinary team constitute a theoretical contribution to the enrichment of knowledge, which on palliative care should be available to professionals who are dedicated to providing this care. In addition to be a tool to provide personalized care from the biological, psychological, social and spiritual dimensions identified in these patients and their caregivers. The development of Palliative Care in Cuba, the work projections and the characteristics of the interdisciplinary team in the current Cuban context, would provide knowledge on the current status of this topic for health professionals in the country and increase the level of excellence In the attention, a great strength of the Palliative Care in the country has been the training of the personnel, which should continue, assimilating academic accreditation figures, such as graduates and master's degrees.

\section{Conflicts of interest}

No potential conflict of interest exists.

\section{References}

1. Aries P (1993) El hombre ante la muerte. Taurus Ediciones, S.A. Madrid, España

2. Gala León FJ, Lupiani M, Rojas R (2002) Actitudes psicológicas ante la muerte y el duelo. Una revisión conceptual. Cuadernos de Medicina Forense.

3. Saunders C Foreword, en Doyle, D, Hanks G, Cherny N (2004) Oxford textbook of Palliative Medicine, $3^{\text {rd }}$ edtn Oxford University Press. New York.

4. Reyes M, Nervi F (2000) Cuidados Paliativos y control de síntomas en Chile. La experiencia de la clínica familiar. Revista de Estudios Médicos Humanísticos. 11: 11.

5. Arranz P, Barbero J, Barreto P, y Bayés R (2003) Intervención emocional en Cuidados Paliativos Modelos y Protocolos. Editorial Ariel S.A. Barcelona. España.

6. Grau J (2016) Informe al Grupo Nacional de Oncología sobre estado actual de la implementación de los cuidados paliativos. Documento inédito, abril del.

7. Centeno C (2008) Historia de los Cuidados Paliativos y Movimiento Hospice. SECPAL.

8. Sánchez Díaz I (2006) Educación Médica y Medicina paliativa. Pontificia Universidad Católica de Chile. Revista de estudios Médicos Humanísticos.

9. Grau J, Chacón M, Reyes MC (2012) Guía de cuidados para familiares de enfermos crónicos avanzados. La Habana: ECIMED.

10. Organización Mundial de la Salud (2008) Consulta

11. Chacón M, Grau J, Reyes MC (2012) Prevención y control del estrés laboral y el desgaste. Guía para profesionales que trabajan con enfermos crónicos avanzados. La Habana: ECIMED.

12. OMS (2015) Cuidados Paliativos: por dónde empezar. Guía práctica: OMS

13. Grau J, Chacón M, Reyes MC (2008) Los Cuidados Paliativos al paciente oncológico en Cuba. Periodos y etapas (Pasado y Presente). Documento impreso.

14. Centeno C (2013) Historia de los cuidados paliativos y el movimiento. Hospice. Sociedad Española de Cuidados Paliativos.

15. Sepal.com Sociedad Española de Cuidados Paliativos.

16. Reyes Méndez MC, Rodríguez Rebustillo M, Bermúdez Sarguera R (2013) Caracterización del proceso de enseñanza de los cuidados paliativos al paciente oncológico terminal en la carrera de Medicina Facultad de Ciencias Médicas "10 de Octubre", durante el curso 2005-2006. Pedagogía Universitaria 12. 
17. Reyes MC, Grau J, Chacón M (2009) Cuidados paliativos en pacientes con cáncer avanzado: 120 preguntas y respuestas. La Habana ECIMED.

18. Strand Jacob J, KamdarMihir M, Carey Elise C (2013) La importancia de los cuidados paliativos Mayo Clin Proc 88: 859-865.
19. De Lima L, Perez-Castells M, Berenguel M, Monti C, Aguilar A, Ahumada M (2013) Indicadores de Cuidado Paliativo ALCP. Houston: IAHPC Press.

20. Anuario Estadístico de Salud Pública (2012) La Habana: MINSAP.

Copyright: @2018 Sáez MF. This is an open-access article distributed under the terms of the Creative Commons Attribution License, which permits unrestricted use, distribution, and reproduction in any medium, provided the original author and source are credited. 